\title{
염증성 하부 뇌신경 마비 후 연하 장애: 증례보고
}

\author{
박찬혁 ${ }^{1}$, 김창환 ${ }^{1}$, 좌경림 ${ }^{1}$, 정한영 ${ }^{1}$, 김명옥 ${ }^{1}$, 김지원 ${ }^{2}$ \\ 인하대학교 의과대학 ${ }^{1}$ 재활의학교실, ${ }^{2}$ 이비인후과학교실
}

\section{Dysphagia after Multiple Lower Cranial Nerves Palsy Induced by Inflammatory Lesion: A Case Report}

\author{
Chan Hyuk Park ${ }^{1}$, Chang Hwan Kim ${ }^{1}$, Kyung Lim Joa ${ }^{1}$, Han Young Jung ${ }^{1}$, Myeong Ok Kim¹, Ji Won Kim² \\ Departments of ${ }^{1}$ Physical \& Rehabilitation Medicine and ${ }^{2}$ Otolaryngology, Inha University School of Medicine, Incheon, Korea
}

\begin{abstract}
Speech and swallowing disorder is frequently observed in stroke, brain injury, tumors, and radiation therapy. A 65-yearold woman was admitted to otolaryngology department due to dysphagia and hoarseness. These symptoms occurred two weeks after upper respiratory infection (URI). She was diagnosed with inflammatory multiple lower cranial nerves by Videofluroscopic Swallowing Study (VFSS), MRI, and neurophysiologic examinations. Shaker's exercise for dysphagia has been performed, and the dysphagia has improved after two months. However the hoarseness persisted, and this has been improved with thyroplasty. Dysphagia by unilateral inflammatory multiple lower cranial nerve palsy would be a rare complication of URI, and we experienced a case of multiple lower cranial neuropathy with successful management.
\end{abstract}

Key Words: lower cranial nerves, dysphagia

\section{Introduction}

Dysphagia and hoarseness are frequently observed in central nervous system disorders, neurodegenerative diseases, peripheral nervous system disorders, neuromuscular junction disorders, myopathies, local ana-

Received November 21, 2017

Revised (1st) March 19, 2018, (2nd) May 4, 2018

Accepted May 25, 2018

Corresponding Author: Chang Hwan Kim

Department of Physical \& Rehabilitation Medicine, Inha University School of Medicine, 27 Inhang-ro, Jung-gu, Incheon 22332, Korea

Tel: 82-32-890-2480, Fax: 82-32-890-2486, E-mail: jacob.kim@inha.ac.kr

This research was supported by Basic Science Research Program through the National Research Foundation of Korea (NRF) funded by the Ministry of Education (2010-0020163). tomical lesions, and psychogenic disorders. ${ }^{1}$ However, the cranial neuropathy induced dysphagia with voice change is rarely reported. Lower cranial nerves (LCN) associated with these symptoms include glossopharyngeal (CN IX), vagal (CN X), accessory (CN XI) and hypoglossal (CN XII) nerves. ${ }^{2}$ The causes of LCN palsy are genetic, vascular, traumatic, iatrogenic, infectious, immunologic, metabolic, nutritional, degenerative, or neoplastic diseases. ${ }^{2}$ It is not common to develop dysphagia by affecting LCN after infection.

Because there are diverse causes of dysphagia and voice changes, the differential diagnosis is important for the proper treatment and rehabilitation. The purpose of this case is to emphasize the accurate diagnosis
Copyright $\odot$ by Korean Association of EMG Electrodiagnostic Medicine
This is an Open Access article distributed under the terms of the Creative Commons Attribution Non-Commercial License (http://creativecommons.org/licenses/by-nc/4.0) which permits unrestricted non-commercial use, distribution, and reproduction in any medium, provided the original work is properly cited. 
using electromyography of unilateral LCN palsy after upper respiratory infection (URI) which could be easily neglected as a cause of these disorders.

\section{Case Report}

A 65-year-old woman was admitted to otolaryngology department due to dysphagia and hoarseness. Her medical history included hypertension, diabetes mellitus, and rheumatoid arthritis without history of genetic disease or toxic exposure. Two weeks after URI, dysphagia and voice change were occurred. She was admitted because she complained of dysphagia.

On physical examination, muscle power and reflexes of all extremities were preserved, there were no sensory symptoms. Also there was no shingles on her skin. The gag reflex was preserved, but vocal change and wet voice were noted after swallowing screening test. Soft palate was bilaterally elevated (CN IX) and tongue deviation (CN XII) was not observed. Shoulder shrugging shows the difference between left and right $(\mathrm{CN}$ $\mathrm{XI})$ and hoarseness (CN X) was noted.

In laboratory tests, $\mathrm{CBC}$ was normal but $\mathrm{CRP}(2.4 \mathrm{mg} / \mathrm{dl})$ and ESR (52 mm/hr) were increased.

On laryngoscopy, 2 weeks after dysphagia, left vocal cord paralysis with intact airway patency and salivary pooling was shown, and there was no ulceration or vesicular lesion (Fig. 1).

Videofluoroscopic Swallowing Study (VFSS), 2 weeks after dysphagia, revealed delayed aspiration due to residue in vallecular space and pyriform sinus with cough in $9 \mathrm{cc}$ liquid while there was penetration without cough in $3 \mathrm{cc}$ and $6 \mathrm{cc}$ liquid. We also observed markedly decreased pharyngeal peristalsis and velopharyngeal insufficiency in pharyngeal phase (Fig. 1B). We recommended Shaker's exercise for dysphagia.

In cranial nerve Magnetic Resonance Image (MRI), performed at the same time as other evaluations, there were asymmetric mild thickening in cisternal segment of left CN X/XI, glossopharyngeal sulcus area and pars nervosa of jugular foramen on Fluid Attenuated Inversion Recovery (FLAIR) and enhanced Fast Spoiled Gradient Echo (FSPGR) image and prominent venous plexus in root exit zone area of CN IX, X, XII. These findings were correlated with inflammatory condition such as neuritis (Fig. 2).

Both upper and lower extremities nerve conduction studies (NCS) including F-waves were normal. In cranial NCS, although including facial, trigeminal, and blink reflex studies were within normal limits, accessory nerves were abnormal in left side (Table 1). The electromyography of left thyroarytenoid showed $2+$ fibrillations and positive sharp waves with no motor units. The left sternocleidomastoid and tongue muscles (CN IX) showed abnormal spontaneous activities due to denervation. Unlike the left side, no specific physical findings were observed on the right side (Table 2).

We finally diagnosed this dysphagia caused by unilat-
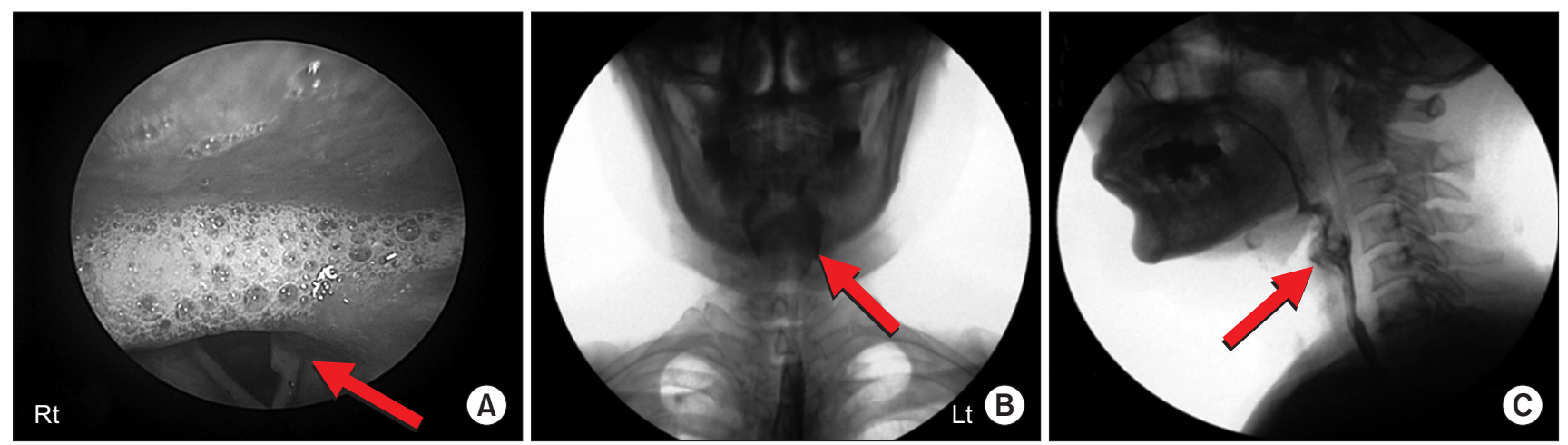

Fig. 1. (A) Laryngoscopy observed left vocal cord palsy with intact airway patency (there was no ulceration or vesicular lesion), and videofluoroscopic swallowing study (VFSS) showed residue in vallecular space, pyriform sinus in AP (B) and lateral view (C). 

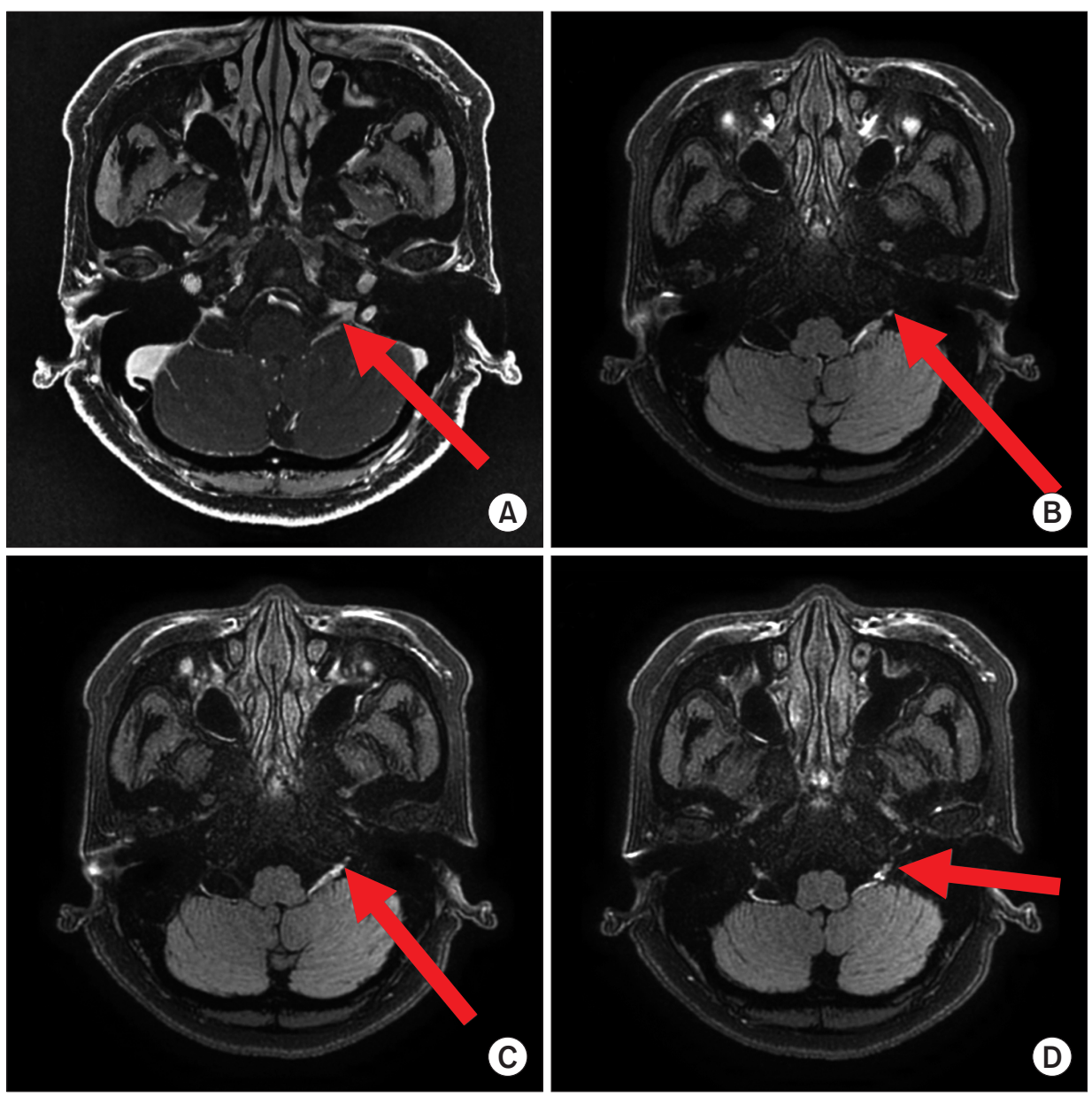

Fig. 2. Asymmetric mild nerve thickening in cisternal segment of left $\mathrm{CN}$ $\mathrm{X} / \mathrm{XI}$, glossopharyngeal sulcus area and pars nervosa of jugular foramen on enhanced Fast Spoiled Gradient Echo (FSPGR) (A) and FLAIR image (B), (C), (D) and enhanced FSPGR image and prominent venous plexus in root exit zone area of CN IX,X,XII.

Table 1. Motor and Sensory Nerve Conduction Studies

\begin{tabular}{|c|c|c|c|c|c|c|}
\hline & \multicolumn{3}{|c|}{ Left side } & \multicolumn{3}{|c|}{ Right side } \\
\hline & Lat. (ms) & Amp. $(\mathrm{mV})$ & $\mathrm{CV}(\mathrm{m} / \mathrm{s})$ & Lat. (ms) & Amp. $(\mathrm{mV})$ & $\mathrm{CV}(\mathrm{m} / \mathrm{s})$ \\
\hline \multicolumn{7}{|l|}{ Motor } \\
\hline Faical nerve (Nasialis) & 4 & 1.5 & & 4.0 & 1.3 & \\
\hline Accessory & $2.5^{*}$ & $2.9^{*}$ & & 2.1 & 3.2 & \\
\hline Median & 3.1 & 5 & 59.3 & 3.2 & 5.1 & 58.5 \\
\hline Ulnar & 2.6 & 6.7 & 59.7 & 2.5 & 5.8 & 62.2 \\
\hline Tibial & 4.9 & 6.1 & 52.9 & & & \\
\hline Peroneal (TA) & 3.2 & 4.5 & & & & \\
\hline Sensory & Lat. (ms) & Amp. $(\mu \mathrm{V})$ & $\mathrm{CV}(\mathrm{m} / \mathrm{s})$ & Lat. (ms) & Amp. $(\mu \mathrm{V})$ & $\mathrm{CV}(\mathrm{m} / \mathrm{s})$ \\
\hline Median & 3.2 & 25.2 & 43.5 & 3.3 & 23.6 & 43.4 \\
\hline Ulnar & 3.1 & 35.6 & 45.9 & 2.9 & 40.9 & 47.6 \\
\hline Peroneal & 2.8 & 9.3 & 49.6 & & & \\
\hline Sural & 3.1 & 10.7 & 44.9 & & & \\
\hline
\end{tabular}

*: abnormal, Lat.: latency, Amp.: amplitude, CV: conduction velocity, TA: Tibialis anterior

eral LCN palsy involving CN IX, X, XI, XII.

Two months after onset, there was a few residues in vallecular space and pyriform sinuses in VFSS, and in electromyography, a few motor units were noted in the left thyroarytenoid and no abnormal findings were observed in the other muscles. As a result, she removed Levin-tube. However, because of voice change without improvement for 5 months onset, tyroplasty was per- 
Table 2. Initial Needle Electromyographic Examinations

\begin{tabular}{|c|c|c|c|c|c|c|c|}
\hline \multirow{2}{*}{ Muscle } & \multicolumn{3}{|c|}{ Abnormal spontaneous activites } & \multicolumn{3}{|c|}{ MUPs } & \multirow{2}{*}{ Interfer. } \\
\hline & Fibs & PSW & $\| A$ & Poly & Amp. & Dur & \\
\hline \multicolumn{8}{|l|}{ Motor } \\
\hline Lt. Thyroarytenoid & $2+$ & $2+$ & $(-)$ & & & & NMU \\
\hline Sternocleidomastoid & $2+$ & $2+$ & $(-)$ & $(-)$ & $\mathrm{N}$ & $\mathrm{N}$ & $\mathrm{R}$ \\
\hline Tongue & $1+$ & $1+$ & $(+)$ & $(-)$ & $\mathrm{N}$ & $\mathrm{N}$ & $\mathrm{R}$ \\
\hline Frontalis & $(-)$ & $(-)$ & $(-)$ & $(-)$ & $\mathrm{N}$ & $\mathrm{N}$ & $\mathrm{N}$ \\
\hline Orbicularis oculi & $(-)$ & $(-)$ & $(-)$ & $(-)$ & $\mathrm{N}$ & $\mathrm{N}$ & $\mathrm{N}$ \\
\hline Nasalis & $(-)$ & $(-)$ & $(-)$ & $(-)$ & $\mathrm{N}$ & $\mathrm{N}$ & $\mathrm{N}$ \\
\hline Orbicularis oris & $(-)$ & $(-)$ & $(-)$ & $(-)$ & $\mathrm{N}$ & $\mathrm{N}$ & $\mathrm{N}$ \\
\hline Masseter & $(-)$ & $(-)$ & $(-)$ & $(-)$ & $\mathrm{N}$ & $\mathrm{N}$ & $\mathrm{N}$ \\
\hline Cricothyroid & $(-)$ & $(-)$ & $(-)$ & $(-)$ & $\mathrm{N}$ & $\mathrm{N}$ & $\mathrm{N}$ \\
\hline Rt. Thyroarytenoid & $(-)$ & $(-)$ & $(-)$ & $(-)$ & $\mathrm{N}$ & $\mathrm{N}$ & $\mathrm{N}$ \\
\hline Sternocleidomastoid & $(-)$ & $(-)$ & $(-)$ & $(-)$ & $\mathrm{N}$ & $\mathrm{N}$ & $\mathrm{N}$ \\
\hline Tongue & $(-)$ & $(-)$ & $(-)$ & $(-)$ & $\mathrm{N}$ & $\mathrm{N}$ & $\mathrm{N}$ \\
\hline Cricothyroid & $(-)$ & $(-)$ & $(-)$ & $(-)$ & $\mathrm{N}$ & $\mathrm{N}$ & $\mathrm{N}$ \\
\hline
\end{tabular}

MUPs: motor unit potentials, Interfer.: interference pattern, Fibs: fibrillation potentials, PSW: positive sharp waves, IIA: Increased insertion activity, Poly: polyphasia, Dur: duration, N: normal, NMU: no motor unit, R: reduced recruitment

formed, and the hoarseness improved.

\section{Discussion}

Dysphagia and hoarseness are commonly caused by various diseases, ${ }^{1}$ and cranial neuropathy is rarely seen in patients presenting with swallowing impairment. ${ }^{3}$ The most common cause of multiple cranial neuropathy is tumor, followed by vascular disease, trauma and infections. ${ }^{4}$ The cranial nerve associated with dysphagia is cranial nerve V, VII, IX, X, XII. It is a symptom seen in LCN palsy when appealing hoarseness and dysphagia like this. LCN injury could lead to dysphagia, coughing, speech disturbance, taste or autonomic function, neuralgia, swallowing disorder, head, pharyngeal or neck pain. In tumorous conditions, the complex anatomy of the vital structures at the skull base makes surgical resection or biopsy of lesions involving this area extremely difficult. $^{5}$

LCN palsy has genetic, vascular, traumatic, iatrogenic, infectious, immunologic, metabolic, nutritional, degenerative, or neoplastic casues. ${ }^{2}$ According to LCN lesions various syndromes are also called Vernet-syndrome, Jugular-foramen-syndrome, Garcin-syndrome, and Villaret's-syndrome associated with varicella-zoster virus. ${ }^{2}$

The CN palsy by general infection is different from this. The difference from Villaret's syndrome, with a complete unilateral IX-XII cranial nerve palsy with Horner's sign, is no involvement of cranial sympathetic nerve. ${ }^{6}$ Our patient is distinguished from RamseyHunt-syndrome because there is no facial nerve palsy, otic pain, and herpetic vesicles. ${ }^{2}$ It is different from jugular foramen syndrome because there is no cranial, cervical pain and no herpetic eruption of skin. It is also one of the other features that is not enhanced around the jugular foramen. ${ }^{3}$ It differs from Garcin's syndrome because there is no proptosis. ${ }^{7}$ No abnormality in upper and lower NCV study and unilateral LCN palsy was also different from Guillain-Barré Syndrome. ${ }^{8}$

Especially, dysphagia can lead to pneumonia, malnutrition, dehydration, and increased mortality. ${ }^{3}$ Since the initial diagnosis, this has slowed down and permanent impairment occurs, when symptoms occur, accurate diagnosis and evaluation. ${ }^{9}$ In general, MRI, cerebrospinal fluid (CSF) study, NCS/electromyography and VFSS are performed for diagnosis. Treatment is usually conservative measures such as shaker's exercise for dysphagia ${ }^{9}$ and anti-inflammatory, antiviral agents. ${ }^{10}$

We diagnosed our patient CN IX (glossopharyngeal nerve), CN X (vagus nerve), CN XI (accessory nerve), and CN XII (hypoglossal nerve) palsy with physical examination, VFSS, laryngoscopy, electromyography, and 
MRI for differential diagnosis.

In our case, we considered that intracranial edema due to inflammatory or immune process would be a cause of LCN. ${ }^{3}$ The exact cause of viral etiology or autoimmune attack cannot be revealed, the primary notice of LCN with clinical neurophysiologic examination followed by cranial nerve MRI has revealed the exact location and extent of disorders.

And the normal nerve conduction study with nonuniform denervation processes in cranial nerve innervated muscles would be associated with relatively mild cranial nerve injury except for the no motor unit observed in muscles innervated by recurrent laryngeal nerve. The limitation of this case is that there are no virology tests including CSF study. If these were performed, and antiviral agents would be applied according to virus etiologies, symptoms could be expected to improve earlier.

In conclusion, we have experienced LCN palsy due to intracranial lesion which might be associated with inflammatory or immune attack. And this case dysphagia was successfully managed by conservative measures, and voice changes corrected with surgery.

\section{References}

1. Cook IJ: Diagnostic evaluation of dysphagia. Nat Clin Pract Gastroenterol Hepatol 2008: 5: 393-403

2. Finsterer J, Grisold W: Disorders of the lower cranial nerves. J Neurosci Rural Pract 2015: 6: 377-391

3. Yeom J, Song YS, Lee WK, Oh BM, Han TR, Seo HG: Diagnosis and clinical course of unexplained dysphagia. Ann Rehabil Med 2016: 40: 95-101

4. Keane JR: Multiple cranial nerve palsies: Analysis of 979 cases. Arch Neurol 2005: 62: 1714-1717

5. Patmore H, Jebreel A, Uppal S, Raine CH, McWhinney P: Skull base infection presenting with multiple lower cranial nerve palsies. Am J Otolaryngol 2010: 31: 376-380

6. Tiliket C, Petiot P, Arpin D, Mornex JF, Mornex F, Tournut P, et al: Clinical and radiological aspects of villaret's syndrome. Clin Neurol Neurosurg 1996: 98: 194-196

7. Alapatt JP, Premkumar S, Vasudevan RC: Garcin's syndromea case report. Surg Neurol 2007: 67: 184-185

8. Mengi T, Secil Y, Incesu TK, Arici S, Akkiraz ZO, Gurgor N, et al: Guillain-barre syndrome and swallowing dysfunction. J Clin Neurophysiol 2017: 34: 393-399

9. Langmore SE, Pisegna JM: Efficacy of exercises to rehabilitate dysphagia: A critique of the literature. Int J Speech Lang Pathol 2015: 17: 222-229

10. Gilden D, Cohrs RJ, Mahalingam R, Nagel MA: Neurological disease produced by varicella zoster virus reactivation without rash. Curr Top Microbiol Immunol 2010: 342: 243-253 